\title{
СРАВНИТЕЛЬНЫЙ АНАЛИЗ КОНСОЛИДИРОВАННОГО БЮДЖЕТА В СРЕДНЕМ ПО РОССИИ И В РЕГИОНАХ СКФО
}

\author{
(c) 2021 Магомадов Эмин Мухадинович
}

кандидат экономических наук, доцент кафедры учета, анализа и аудита в цифровой экономике Чеченский государственный университет, Россия, Грозный

(c) 2021 Башаев Асхаб Алманович

3 курс Института экономики и финансов Чеченский государственный университет, Россия, Грозный

(c) 2021 Ильясов Тамерлан Русланович

3 курс Института экономики и финансов Чеченский государственный университет, Россия, Грозный

Данная статья посвящена оценке и анализу консолидированного бюджета СКФО. Рассмотрены теоретические основы, а также статистические данные бюджета. Исследованы поступление и отток средств в бюджет. Выявлены расходы госбюджета. В заключении, рассмотрена программа для преодоления дефицита бюджета СКФО.

Ключевые слова: доходы, расходы, консолидированный бюджет, анализ, налоги, дотации.

Госбюджет консолидированный всегда используется обширно, то есть он используется в ходе планирования, а также при анализе ключевых показателей бюджетной концепции. Те самые налоги, которые каждый день платят граждане РФ, идут в казну государства. Часто можно услышать, что государственный бюджет называют «кошельком» или «мешком». Госбюджет - это основной финансовый план государства, некая смета его доходов и расходов, который содержит в себе источники доходов и направления расходов. Госбюджет разрабатывает правительство в лице Министерства финансов, который передает ее в Государственную Думу, соответственно бюджет принимается Госдумой в виде законопроекта, который утверждается Советом Федерации, подписывается президентом и далее реализуется, исполняется правительством.

Бюджет содержит в себе два элемента. Во-первых, это доходы, очевидно, что это те самые налоги, которые мы платим каждый день, так же штрафы, прибыль госпредприятий, продажа собственности(приватизация) и т.д. Помимо доходов имеются и расходы, это второй неотъемлемый элемент бюджета. Например, жалования госслужащих, пенсии, расходы на оборону.

Правительственный бюджет, представляет собой главный экономический проект нашей страны, который представляет правительству РФ реальную экономическую власть и возможность ее реализации. Госбюджет отображает объем финансовых ресурсов, требуемых стране, и тем самым определяет налоговую политику в государстве. Госбюджет закрепляет конкретные сферы затрат, перераспределение национального дохода и ВВП, что позволяет ему представляться как результативный регулятор экономики.

Необходимо отметить, что консолидированный бюджет не является юридическим документом по причине того, что он не утверждается ни одним законодательным органом власти.

Хотелось бы отметить, что в составе бюджета образуются целевые бюджетные фонды, которые создаются за счет доходов, используются они по целевому назначению, то есть, данные доходы используются по отдельной смете. В целевой бюджет входят (рис. 1) [1].

Бюджетная система РФ представляет собой совокупность всех бюджетов страны и состоит из 3 уровней (рис. 2).

Следует отметить, что понятие консолидированный бюджет было введено в 1991 году.

Данный документ уже недействителен, так как он устарел, но имеется документ, который действует и на данный момент. «Бюджетный кодекс Российской Федерации» от 31.07 .1998 N 145-Ф3 [1]

Статья 6 Бюджетного кодекса РФ дает нам формулировки и понятия, которые применяются в 2021 году.

Консолидированный бюджет субъектов РФ объединяет рис. 3 [2]. 


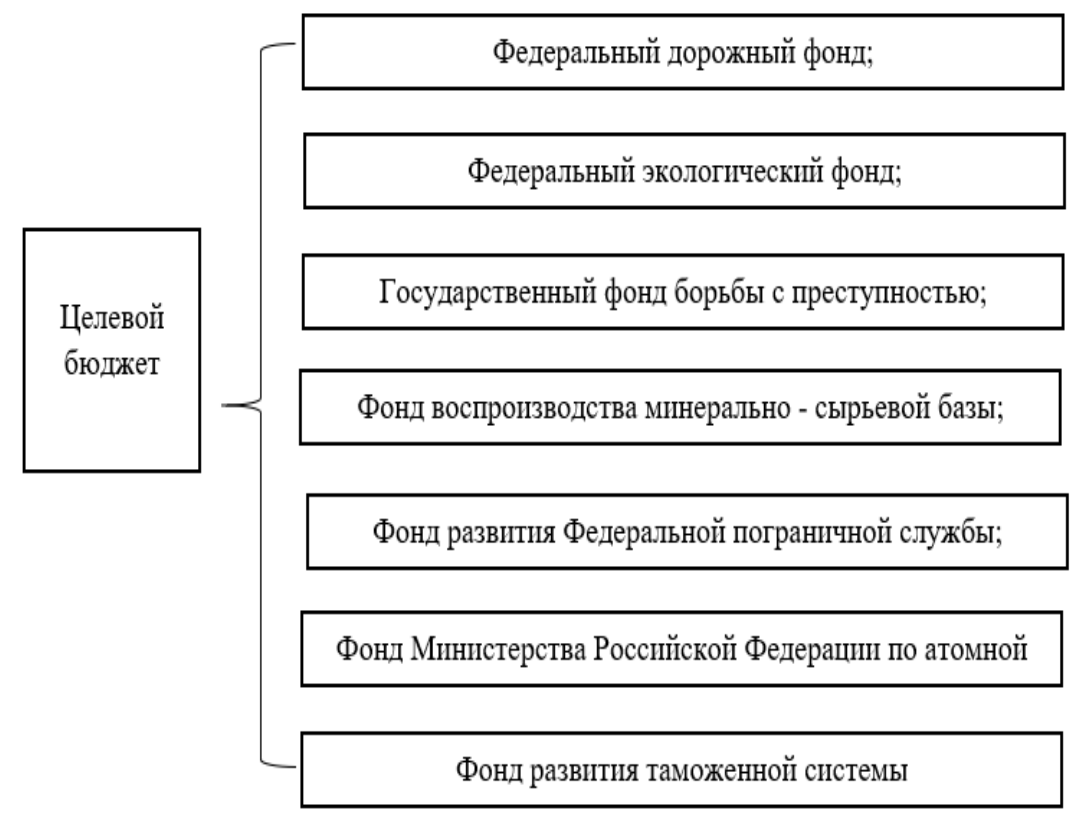

Рисунок 1. Целевой бюджет

Федеральный бюджет

Бюджеты государственных внебюджетных фондов, таких как: Пенсионный фонд, Фонд социального страхования, Фонд обязательного медицинского страхования.

Региональные бюджеты

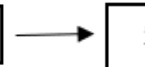

Это бюджеты краев, областей, республик, автономных округов. Так же относятся региональные внебюджетные фонды. Региональный уровень регламентируется законами субъектов РФ

Местные бюджеты

Бюджеты городов, городских округов, а также бюджет городских и сельских поселений. Муниципальный уровень регламентируется муниципальными правовыми актами

Рисунок 2. Уровни

\begin{tabular}{|c|}
\hline Консолидиро- \\
ванный бюджет \\
объединяет
\end{tabular}

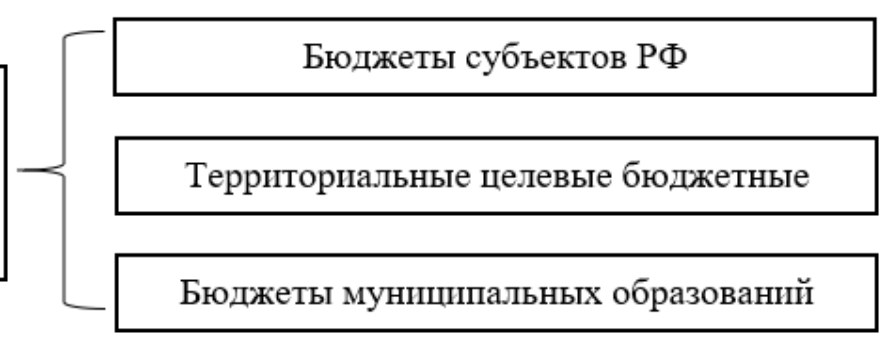

Рисунок 3. Консолидированный бюджет 
Все вместе это будет составлять понятие консолидированного бюджета.

Бюджет - форма формирования и расходования средств, которые предназначены для финансового обеспечения задач и функций как государства, так и местного самоуправления;

Под доходами бюджета подразумеваются поступления денежных средств. Но также имеется и исключение. В соответствии с статьей 6 Бюджетного Кодекса РФ под исключение попадают денежные средства, направленные на финансирование дефицита бюджета.

Под расходами подразумеваются денежные средства, выплачиваемые из бюджета.

Все вместе это будет составлять понятие консолидированного бюджета.

Каждый год, на официальном сайте Министерства финансов выкладывают информацию об исполнении консолидированного бюджета. То есть, любой гражданин РФ может посмотреть, например, на что идут уплаченные им налоги. Информация представлена в виде таблицы Excel.

В данной статье рассматривается конкретный субъект консолидированного бюджета -
Северо-Кавказский федеральный округ.

За 2017, 2018, 2019 годы проведен сравнительный анализ исполнения консолидированных бюджетов РФ по федеральным округам, оценены структура доходов и расходов бюджетов по субъектам СКФО [3].

В 2017 году по данным Минфина сумма доходов в консолидированный бюджет составила 402805179 млн. руб. В данную сумму входят показатели, показанные на рис. 4.

- Неналоговые доходы согласно данным, представленным на официальном сайте Минфина за 2017 год, в консолидированный бюджет составили 11млн. рублей (данные представлены в приложении 1)

- Безвозмездные поступления от других бюджетов бюджетной системы РФ по данным Минфина за 2017 год составили 234 млн. руб. В эту сумму входят дотации, субсидии, субвенции, а также иные межбюджетные трансферты. Данные представлены в рисунке 6.

По данным таблицы может сделать вывод, что с каждым годом доходы в консолидированный бюджет увеличиваются. Темп роста за

\begin{tabular}{|c|c|c|c|}
\hline \multirow{2}{*}{$\begin{array}{c}\text { Наименование } \\
\text { субъекта РФ }\end{array}$} & \multicolumn{3}{|c|}{ Итого доходов } \\
\hline & 2017 & 2018 & 2019 \\
\hline $\begin{array}{c}\text { Северо-Кавказский } \\
\text { ФО }\end{array}$ & 402805179 & 448084446 & 508016877 \\
\hline Респ. Дагестан & 107278278 & 119874135 & 134787231 \\
\hline Респ. Ингушетия & 23000555 & 24819993 & 26715713 \\
\hline $\begin{array}{c}\text { Кабардино-Балкар. } \\
\text { Респ. }\end{array}$ & 29390432 & 35996642 & 41206632 \\
\hline $\begin{array}{c}\text { Карачаево-Черкес. } \\
\text { Респ. }\end{array}$ & 24039203 & 26504900 & 30341743 \\
\hline $\begin{array}{l}\text { Респ. Северная } \\
\text { Осетия }\end{array}$ & 27733873 & 32997269 & 38512792 \\
\hline Чеченская Респ. & 77477402 & 80806496 & 97634931 \\
\hline $\begin{array}{c}\text { Ставропольский } \\
\text { край }\end{array}$ & 113885437 & 127085011 & 138817836 \\
\hline
\end{tabular}

Рисунок 4. Налоговые доходы консолидированного бюджета за 2017-2019 г.г. 


\begin{tabular}{|c|c|c|c|c|c|c|c|c|c|c|c|}
\hline $\begin{array}{c}\text { Наиме- } \\
\text { нование } \\
\text { субъекта } \\
\text { РФ }\end{array}$ & $\begin{array}{l}\text { Итого } \\
\text { дохо- } \\
\text { дов }\end{array}$ & $\begin{array}{l}\text { Налого- } \\
\text { вые до- } \\
\text { ходы }\end{array}$ & $\begin{array}{l}\text { Налог } \\
\text { на при- } \\
\text { быль } \\
\text { органи- } \\
\text { заций }\end{array}$ & $\begin{array}{l}\text { Налог } \\
\text { на до- } \\
\text { ходы } \\
\text { физиче- } \\
\text { ских } \\
\text { лиц }\end{array}$ & Акцизы & $\begin{array}{l}\text { Налог } \\
\text { на до- } \\
\text { бычу } \\
\text { полез- } \\
\text { ных ис- } \\
\text { копае- } \\
\text { мых }\end{array}$ & $\begin{array}{l}\text { Транс- } \\
\text { порт- } \\
\text { ный } \\
\text { налог }\end{array}$ & $\begin{array}{l}\text { Налог } \\
\text { на иму- } \\
\text { щество } \\
\text { органи- } \\
\text { заций }\end{array}$ & $\begin{array}{l}\text { Налог } \\
\text { на иму- } \\
\text { шество } \\
\text { физ. } \\
\text { лиц }\end{array}$ & $\begin{array}{l}\text { Земель- } \\
\text { ный } \\
\text { налог }\end{array}$ & $\begin{array}{l}\text { Прочие } \\
\text { налого- } \\
\text { вые до- } \\
\text { ходы }\end{array}$ \\
\hline $\begin{array}{l}\text { Северо- } \\
\text { Кавказ- } \\
\text { ский ФО }\end{array}$ & $\begin{array}{l}402 \\
805 \\
179\end{array}$ & $\begin{array}{c}167903 \\
359\end{array}$ & $\begin{array}{c}26395 \\
329\end{array}$ & $\begin{array}{c}65339 \\
572\end{array}$ & $\begin{array}{c}26983 \\
713\end{array}$ & 133000 & $\begin{array}{c}3157 \\
602\end{array}$ & $\begin{array}{c}17145 \\
101\end{array}$ & 949539 & $\begin{array}{l}4879 \\
332\end{array}$ & $\begin{array}{l}11137 \\
259\end{array}$ \\
\hline
\end{tabular}

Рисунок 5. Налоги за 2017 год по СКФо

\begin{tabular}{|c|c|c|c|c|c|}
\hline $\begin{array}{c}\text { Наименование } \\
\text { субъекта РФ }\end{array}$ & $\begin{array}{c}\text { Безвозмездные } \\
\text { поступления от } \\
\text { других бюджетов } \\
\text { бюджетной си- } \\
\text { стемы Российской } \\
\text { Федерации }\end{array}$ & дотации & субсидии & субвенции & $\begin{array}{l}\text { иные межбюджет- } \\
\text { ные трансферты }\end{array}$ \\
\hline $\begin{array}{c}\text { Северо-Кавказ- } \\
\text { ский ФО }\end{array}$ & 234893913 & 153188180 & 42056638 & 29588933 & 10023129 \\
\hline $\begin{array}{c}\text { Республика. } \\
\text { Дагестан }\end{array}$ & 74793723 & 56294334 & 8714722 & 7616136 & 2168531 \\
\hline $\begin{array}{l}\text { Республика. } \\
\text { Ингушетия }\end{array}$ & 18736451 & 9311820 & 4309971 & 4299097 & 815563 \\
\hline $\begin{array}{c}\text { Кабардино- } \\
\text { Балкар. Рес- } \\
\text { публика. }\end{array}$ & 15692974 & 10236152 & 3397993 & 1792952 & 265877 \\
\hline $\begin{array}{c}\text { Карачаево- } \\
\text { Черкес. Рес- } \\
\text { публика. }\end{array}$ & 15655679 & 8245556 & 6052900 & 1075181 & 282042 \\
\hline $\begin{array}{c}\text { Республика. } \\
\text { Северная Oce- } \\
\text { тия }\end{array}$ & 13588304 & 8371811 & 2642588 & 1645188 & 891685 \\
\hline
\end{tabular}

Рисунок 6. Безвозмездные поступления в бюджет РФ за 2017 год 
2017-2018 год составил $111,2 \%$. Темп роста за 2018-2019 год составил 113,3\%. Данные для анализа за 2019 год представлены на рисунке 7 [4].

Неналоговые доходы составили 13 млн. руб.

Безвозмездные поступления от других бюджетов бюджетной системы Российской Федерации по данным Минфина за 2018 год составили 261578314 млн. руб. Данные представлены в приложении 1.

Рассчитаны темпы роста в период за 20172018 год. Расчеты проводились по формуле:

Тр $=$ Рнп / Ркп * 100,

где Тр - показатель темпа роста;

Рнп - показатель на начало периода;

Ркп - показатель на конец периода.

Темп роста налоговых доходов в период за 2017-2018 год составляет 111,2\%. Считаем по формуле Тр $=186676306 / 167903359 * 100$.

Неналоговые доходы в период за 2017-2018 год. Темп роста составляет $116,3 \%$.

Безвозмездные поступления в период за 2017-2018 год. Темп роста составляет $111,4 \%$.

Из анализа данных за 2017-2018 год можно сделать вывод, что наблюдается положительная динамика [4].

Анализ темпов роста в период с 2018 год по 2019 год дал следующие результаты:

В 2019 году доходы по СКФО составляют 508016877 млн. руб. Темп роста в период за 2018-2019 г.г. составляет 113,4\%.

Налоговые доходы в 2018 году составляли 186676306 млн. руб., в 2019 году - 188228476 млн. руб. Темп роста составляет $100,9 \%$.

Неналоговые поступления за 2018 год составляют 13701730 млн. руб., за 2019 год - 12160906 млн. руб. Темп роста составляет $88,8 \%$. Наблюдается отрицательная динамика.

Безвозмездные поступления на 2018 год составляют 261578314 млн. руб., на 2019 год - 308542696 млн. руб., темп роста составляет 118,0\%. Анализ за 2018-2019 годы показывает, что наблюдается положительная динамика.

Каждый год Министерство финансов РФ на своем официальном сайте выкладывает информацию не только о доходах консолидированного бюджета, но и так же информацию о расходах.

Проведем сравнительный анализ расходов за 2017,2018,2019 годы в Северо-Кавказском федеральном округе. В период за 2017-2018 год темп роста составил $106,2 \%$, а в период за 2018-2019 год так же наблюдается положительный темп роста, который составляет $116,9 \%$

Согласно данным, представленным в приложении 3, можно сделать вывод, что расходы превышают доходы.

Согласно данным ФНС России по СевероКавказскому федеральному округу в 2018 году сбор налогов по сравнению с 2017 годом увеличился до $10,3 \%$, сумма составила 208,4 млрд. руб. На 1 января 2019 года имеется задолженность по налогам и сборам, сумма задолженности составляет 41,8 млрд. руб. В 2018 году консолидированный бюджет Северо-Кавказского федерального округа был исполнен с профицитом. Сумма профицита составляет 21,7 млрд. руб. 426,4 млрд. руб. составили расходы, а доходы составили 448,1 млрд. руб. Анализ представлен на рисунке 8.

Увеличение расходов зафиксировано в 7 регионах таких, как [5]:

Республика Дагестан-сумма доходов за 2018 год составила 119874135 млн. руб., сумма расходов 107949463 млн. руб. По данным за 2019 год сумма доходов составила 134786173 млн. руб., сумма расходов составила 129598089 млн. руб. Имеется профицит в размере 5188084 млн. руб.

Республика Ингушетия-сумма доходов за

\begin{tabular}{|c|c|c|c|c|c|c|c|c|c|c|c|}
\hline $\begin{array}{c}\text { Наиме- } \\
\text { нова- } \\
\text { ние } \\
\text { субъ- } \\
\text { екта РФ }\end{array}$ & $\begin{array}{l}\text { Итого } \\
\text { дохо- } \\
\text { дов }\end{array}$ & $\begin{array}{l}\text { Налого- } \\
\text { вые до- } \\
\text { ходы }\end{array}$ & $\begin{array}{l}\text { Налог } \\
\text { на при- } \\
\text { быль ор- } \\
\text { ганиза- } \\
\text { ций }\end{array}$ & $\begin{array}{l}\text { Налог на } \\
\text { доходы } \\
\text { физиче- } \\
\text { ских лиц }\end{array}$ & $\begin{array}{l}\text { Ак- } \\
\text { цизы }\end{array}$ & $\begin{array}{l}\text { Налог } \\
\text { на до- } \\
\text { бычу } \\
\text { полез- } \\
\text { ных ис- } \\
\text { копае- } \\
\text { мых }\end{array}$ & $\begin{array}{l}\text { Транс- } \\
\text { порт- } \\
\text { ный } \\
\text { налог }\end{array}$ & $\begin{array}{l}\text { Налог } \\
\text { на иму- } \\
\text { щество } \\
\text { органи- } \\
\text { заций }\end{array}$ & $\begin{array}{l}\text { Налог } \\
\text { на иму- } \\
\text { щество } \\
\text { физ. } \\
\text { лиц }\end{array}$ & $\begin{array}{l}\text { Земель- } \\
\text { ный } \\
\text { налог }\end{array}$ & $\begin{array}{l}\text { Прочие } \\
\text { налого- } \\
\text { вые до- } \\
\text { ходы }\end{array}$ \\
\hline $\begin{array}{c}\text { Северо- } \\
\text { Кавказ- } \\
\text { ский } \\
\text { ФО }\end{array}$ & $\begin{array}{l}448 \\
084 \\
446\end{array}$ & $\begin{array}{c}186676 \\
306\end{array}$ & $\begin{array}{c}27467 \\
107\end{array}$ & $\begin{array}{c}74322 \\
025\end{array}$ & $\begin{array}{r}30 \\
267 \\
815\end{array}$ & 147979 & $\begin{array}{c}3413 \\
730\end{array}$ & $\begin{array}{c}18397 \\
231\end{array}$ & $\begin{array}{c}1258 \\
006\end{array}$ & $\begin{array}{l}4851 \\
915\end{array}$ & $\begin{array}{l}12848 \\
767\end{array}$ \\
\hline
\end{tabular}

Рисунок 7. Налоги за 2018 год по СКФО 


\begin{tabular}{|c|c|c|c|}
\hline \multirow{2}{*}{$\begin{array}{c}\text { Наименование } \\
\text { субъекта РФ }\end{array}$} & \multicolumn{3}{|c|}{ Итого расход } \\
\hline & 2017 & 2018 & 2019 \\
\hline $\begin{array}{c}\text { Северо-Кавказский } \\
\text { ФО }\end{array}$ & 401283998 & 426361384 & 498404984 \\
\hline Респ. Дагестан & 103582346 & 107949463 & 129599147 \\
\hline Респ. Ингушетия & 22883407 & 24513593 & 26062752 \\
\hline $\begin{array}{c}\text { Кабардино-Балкар. } \\
\text { Респ. }\end{array}$ & 32087427 & 34130744 & 38646840 \\
\hline $\begin{array}{c}\text { Карачаево-Черкес. } \\
\text { Респ. }\end{array}$ & 23992103 & 26439130 & 29997710 \\
\hline $\begin{array}{l}\text { Респ. Северная } \\
\text { Осетия }\end{array}$ & 28119478 & 32577247 & 37519810 \\
\hline Чеченская Респ. & 77116624 & 80510766 & 97846265 \\
\hline $\begin{array}{l}\text { Ставропольский } \\
\text { край }\end{array}$ & 113502613 & 120240441 & 138732460 \\
\hline
\end{tabular}

Рисунок 8. Расходы за 2017, 2018, 2019 г.г.

2018 год составила 24819993 млн. руб., сумма расходов 24513593 млн. руб. По данным за 2019 год сумма доходов составила 26715048 млн. руб., сумма расходов составила 26062087 млн. руб. Имеется профицит в размере 652961 тыс. руб.

Кабардино-Балкарская Республика - сумма доходов за 2018 год составила 35996642 млн. руб., сумма расходов - 34130744 млн. руб. По данным за 2019 год сумма доходов составила 41206632 млн. руб., сумма расходов составила 38646840 млн. руб. Имеется профицит в размере 2559791 млн. руб.

Карачаево-Черкесская Республика сумма доходов за 2018 год составила 26504900млн.руб., сумма расходов - 26439130 млн. руб. По данным за 2019 год сумма доходов составила 30340866 млн. руб., сумма расходов составила 29996833 млн. руб. Имеется профицит в размере 344033 тыс. руб.

Республика Северная Осетия - сумма доходов за 2018 год составила 32997269 млн. руб., сумма расходов - 32577247 млн. руб. По данным за 2019 год сумма доходов составила 38510068 млн. руб., сумма расходов составила 37517086 млн. руб. Имеется профицит в размере 992982 тыс. руб.

Чеченская Республика - сумма доходов за 2018 год составила 80806496 млн. руб., сумма расходов - 80510766 млн. руб. По данным за 2019 год сумма доходов - 97634931 млн. руб., сумма расходов - 97846265 млн. руб. Имеется дефицит в размере -211335 тыс. руб.

Ставропольский край- сумма доходов за 2018 год составила 127085011 млн. руб., сумма расходов - 120240441 млн. руб. По данным за 2019 год сумма доходов - 138820874 млн. руб., сумма расходов - 138735498 млн. руб. Имеется профицит в размере 85376 млн. руб.

На 1 ноября 2019 года расходы СевероКавказского федерального округа на заработную плату и начисления на выплаты по оплате труда составили 4224375955 млрд. рублей, что составляет $110.7 \%$ от суммы расходов на 1 ноября 2018 года.

Исходя из вышесказанного, стоит заметить, что Чеченская Республика находится в дефи- 
ците, Карачаево-Черкесская республика имеет небольшой профицит. Большая часть расходов этих двух регионов составляет заработная плата и социальное обеспечение, однако в КЧР имеется много возможностей для трудоустройства молодежи. Это связано с тем, что там сильно развит курортный бизнес, следовательно, у людей больше возможностей для уплаты налогов. Для того, чтобы повысить доход, необходимо донести до всех жителей информацию, связанную с налогами и сборами. Как показывает практика, большинство людей, либо забывают об уплате налога, или же не имеют средств для их оплаты. Для того, чтобы средства появились необходимы рабочие места. Уровень безработицы в Чеченской Республике на 2019 год составляет 8\% и с каждым месяцем растет [6]. Если провести небольшой анализ, то также можно выявить то, что наиболее подверженным к безработице слоем населения является возрастная категория от 18 до 25 лет, в то время, когда в других регионах и в среднем по России, это показатель прямопротивоположный. Если взять для анализа отчёт по другим регионам Российской Федерации, то можно смело утверждать, что дефицит преобладает во множестве регионов. Следовательно, главной проблемой является безработица в регионах и в среднем по России. Исходя из этого, можно сделать вывод, что для уменьшения дефицита бюджета необходимо расширение рынка труда и мобилизация молодежи в разных сферах производственной сферы.

\section{Библиографический список}

1. Бюджетный кодекс Российской Федерации от 31.07.1998 № 145-Ф3 (ред. от 22.12.20) // [Электронный ресурс] // Режим доступа //http://www.consultant.ru/document/cons_doc_LAW_19702// -(дата обращения 04.03.2021)

2. Федеральный закон «О федеральном бюджете на 2019 год и на плановый период 2020 и 2021 годов» от 29.11.2018 N 459-Ф3 (последняя редакция) Консультант плюс[Электронный ресурс] // Режим доступа http:// www.consultant.ru/document/cons_doc_LAW_312362/ -(дата обращения 04.03.2021)

3. Министерство финансов// [Электронный ресурс] // Режим доступа https://minfin.gov.ru/ru/ document/?id_4=129623-dannye_ob_ispolnenii_konsolidirovannykh_byudzhetov_subektov_rossiiskoi_federatsii_ na_1_yanvarya_2020_goda / -(дата обращения 04.03.2021)

4. Федеральное казначейство официальный сайт Казначейства России//[Электронный ресурс]//Режим доступа// https://roskazna.gov.ru/ispolnenie-byudzhetov/konsolidirovannye-byudzhety-subektov///(дата обращения 04.03.2021)

5. Отчет о ходе реализации в 2018 году Стратегии социально-экономического развития Северо-Кавказского федерального округа до 2025 года, утвержденной распоряжением Правительства Российской Федерации от 6 сентября 2010 г.№ 1485-p // [Электронный ресурс] // Режим доступа http://old.economy.gov.ru/wps/wcm/ connect/10b7c8f0-f761-4c41-8054-e3b4042f1ff8/report_SKFO_2018.pdf? MOD=AJPERES\&CACHEID=10b7c8f0 -f761-4c41-8054-e3b4042f1ff8 -(дата обращения 04.03.2021)

6. Территориальный орган федеральной службы государственной статистики по Чеченской республике [Электронный ресурс] // Режим доступа// https://chechenstat.gks.ru/folder/38735-(дата обращения 04.03.2021) 